\title{
Identification and in situ hybridization to mitotic chromosomes of a molecular marker linked to maleness in Anastrepha fraterculus (Wied.)
}

\section{Summary}

The present report shows the molecular identification, isolation and citologically localization of a DNA-sequence from the South American fruit fly Anastrepha fraterculus (DIPTERA: Tephritidae) involved in sex- determination. It belongs to the Tephritidae family, the true fruit flies which are consider a pest of fruit crops. The sex determination system is of vital importance in the genetic control of the fruit fly pest: Sterile Insect Technique which unlike chemical control tactics, is environmentally friendly and does not pose any health concerns. We used in situ hybridization on mitotic chromosomes for localizing the primary sex determination factor in this fruit fly pest. Our results show that in Anastrepha fraterculus the $\mathrm{Y}$ chromosome is responsible for sex determination.

Keywords: fruit flies, sex determination Tephritidae, chromosomes, cell division, aneuploids, Diptera, flies, invertebrates, insects, biotechnology, nucleic acids hybridization, sterile male technique, sterile insect technique
Volume 7 Issue 6 - 2020

\author{
Alicia Basso, Ariane Sonvico \\ Chair of Genetics, Faculty of Agronomy, University of Buenos \\ Aires, Argentina
}

\begin{abstract}
Correspondence: Alicia Basso, Chair of Genetics, Faculty of Agronomy, University of Buenos Aires, Av. San Martin 4453, CI4I7DSE, Ciudad Autónoma de Buenos Aires, Argentina, Email abasso@agro.uba.ar
\end{abstract}

Received: November 24, 2020 | Published: December 07, 2020

\section{Introduction}

Fruit flies occur in two forms -male and female- that differ markedly in their reproductive anatomy and physiology. Sexual chromosomes are functionally responsible that a zigote develops a male or a female. The basic plan of gonadal development in both sexes is female unless testes are induced by factor(s) of the $\mathrm{Y}$ chromosome, known as testis determining factor(s) (TDF). ${ }^{1}$ In many cases, one of the sex chromosomes has become structurally modified while the other has remained unchanged. The structurally modified chromosome is limited to one sex. The South American fruit fly Anastrepha fraterculus (Wied) belongs to the Tephritidae family, the true fruit flies, where only females damage fruits punching out the fruit with their ovipositor in order to lay eggs. This species often shares host fruits with the Mediterranean fruit fly (Medfly) Ceratitis capitata (Wied.), a very resilient species on which abundant research to control it, is achieved. The only non-contaminant and non-modifier method for the environment is the autocidal control where the species is used to control itself by releasing millions of sterilized flies. ${ }^{2-4}$ The problem with fuit fly species is the fact that sterile females do not lose the habit of oviposition. In C. capitata an improvement of the technique is based on linking a genetic marker to the Y-chromosome to produce a sexing strain in order to easily separate, irradiate and release only sterile males. ${ }^{5,6}$ The limiting factor to develop a genetic control strategy is to know the insect system of sex determination. In true fruit flies, females carry 6 pairs of chromosomes, the 1 st pair being an XX. Males carry 6 sets also, but their 1st pair is an XY twosome. This system of sex determination results in an inequality in the dosage of the genes present on the $\mathrm{X}$ chromosomes in male and females. Particularly, in Ceratitis capitata (DIPTERA: Tephritidae), the Y-chromosome has an active role in sex determination ${ }^{7,8}$ opposite to Drosophila where the $Y$ chromosome is not involved in determining sex - rather- it is needed for male fertility. Drosophila sex determination is based on the ratio of $\mathrm{X}$ chromosomes to autosomes. ${ }^{9,10}$

Studies on the Medfly using Y-autosome translocations ${ }^{11,12}$ and deletion mapping ${ }^{13}$ have defined a relatively small segment of the proximal portion of the long arm of the Y chromosome that is sufficient to obtain a male phenotype. From cytological studies, Bedo, ${ }^{14}$ Basso et al. ${ }^{15}$ have shown that the Medfly Y chromosome consists of blocks of C-banded material, suggesting extensive areas of heterochromatin. An X-chromosome polymorphism due to attachment of a B-chromosome- and XL-chromosome, was described by Basso and Lifschitz, where the B-chromosome can be inherited free or attached to X- or Y-chromosome.

The purpose of the present work, is to report the molecular identification, isolation and citologically localization of a DNAsequence from Anastrepha fraterculus (DIPTERA: Tephritidae) involved in sex- determination.

\section{Materials and methods}

DNA Extraction: Genomic DNA extractions from 2 males and 2 virgin females -taken from two inbred strains of A. fraterculuswere performed separately, according to the technique described by Sonvico et al. ${ }^{16}$

Polymerase Chain Reaction: The RAPD/PCR reaction conditions were as described by Sonvico et al., ${ }^{16}$ it was used $1 \mu \mathrm{M}$ random primer PK18 (5'-CCTAGTCGAG-3') or each one of one of these primers: PH15, PK09, PK13 or PK17, (Operon Technologies, Alameda, CA). DNA size markers were 100bp DNA ladder.

Purification of selected DNA fragments: The selected amplified DNA fragments were eluted from the gels and purified with a DNA purification kit: GeneClean (MP Biomedicals), according with the respective manufacturer instructions.

Labelling of DNA fragments: Fragments were labelled with digoxigenin-11-dUTP by random priming according to Boehringer manual and used as a probe in FISH analysis.

Cytology: To obtain cytological preparations, to be used in molecular cytogenetics, we proceeded as follows. The slides were placed in coplin jars with a 3:1 solution of Methanol and acetic acid and kept in the freezer at $-20^{\circ} \mathrm{C}$ until time of use. Neuroblasts of subesophageal ganglion from third instar larvae were used to study mitosis. Dissection was in Ringer's solution, extracting the cerebral ganglion. The tissue was changed to $1 \%$ sodium citrate solution for 15 minutes and then transferred to a 3: 1 solution of Methanol: Glacial Acetic Acid for 60 seconds. For uniform fixation, the tissue was cut into 
small pieces with needles and pipetting (splash). It was immediately passed through a hot plate at $75^{\circ} \mathrm{C}$. The preparations were examined under a phase contrast binocular. Once selected, they were dehydrated for 1-5 minutes in ethanol: $80 \%$ and $100 \%$, air dried and stored in a freezer at $-20^{\circ} \mathrm{C} .^{17}$

FISH: The fluorescence in situ hybridization with probe pK18 on mitotic chromosomes of A. fraterculus, was performed following the protocol by Willhoeft and Franz. ${ }^{18}$

\section{Results}

DNA profiles: Males and females DNA of A. fraterculus were analyzed through RAPD/PCR separately. All the random of A. fraterculus were analyzed through primers tested amplified sequences that appeared to be shared (in terms of length) by both males and female individuals (Figure 1 and data not shown). Some of those random primers amplified -only in males- DNA polymorphic sequences differing in size (Figure 1 and data not shown). Figure 1 shows the amplification products produced by random primers PH15, PK09, PK13, PK17 and PK18. Primer PK18 generated one differential band present only in males (Figure $1 \mathrm{Left}$ ). The band amplified with primer PK18 (Figure 1 Right) was eluted from the gel, purified, labelled with digoxigenine and used as a probe in FISH analysis. The size of the male band is $300 \mathrm{bp}$.

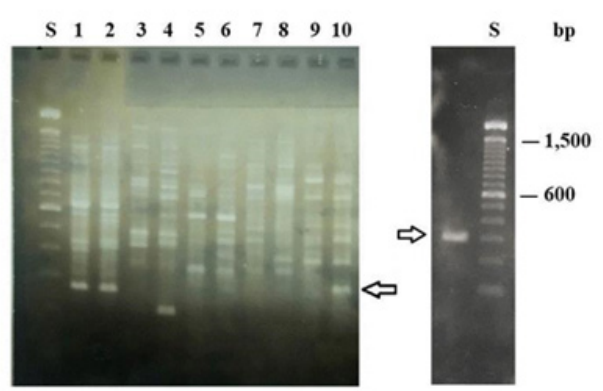

Figure I Left. RAPD-PCR products of amplification using the following random primers: lanes I and 2 PHI5; 3 and 4 PK09; 5 and 6 PKI3; 7 and 8 PKI7; 9 and I0 PK I8. Lanes I, 3, 5, 7 and 9 correspond to females. Lanes 2, 4,6, 8 and 10 correspond to males. S, size markers. Arrow shows the "male band" amplified with primer PKI8. Right. Purified "male band" amplified with primer PKI8.Arrow shows the "male band" used as a probe in Fish analysis.

Fluorescence in situ hybridization: Probe pk18 amplified in males and hybridized a large region on the $\mathrm{Y}$ chromosomes. It also hybridizes the X telomeres. Strain "fraterculus Argentina 1" for brevity "f Arg 1" is our reference strain. Its sexual karyotype is X1Y1 the $\mathrm{X}$-chromosome being acrocentric whereas the Y-chromosome is sub metacentric. ${ }^{19-22}$ The probe strongly marks the proximal region of the long arm of the sub-metacentric Y1-chromosome as well as its entire short arm. A strong signal marks the short arm of the X1chromosome (Figure $2 \mathrm{~A}$ ), while a weaker signal is observed on the long arm telomere (Figure 2A). Other strains bearing Y-chromosome polymorphisms were also tested. These chromosomal variants -a sub-telocentric Y2-chromosome (not shown) and a telocentric Y3chromosome ((Figure 2B and ideogram) are shorter than the Y1chromosome. The probe hybridized the long arm of the Y2-variant (not shown). Probe pK18 completely hybridized the short arm and the long arm of the Y3-chromosome (Figure 2B and ideogram). The short and long arm telomeres of the sexual X1-chromosome were also hybridized on both strains, repeating the pattern of fArg 1 $\mathrm{X}$-chromosome.

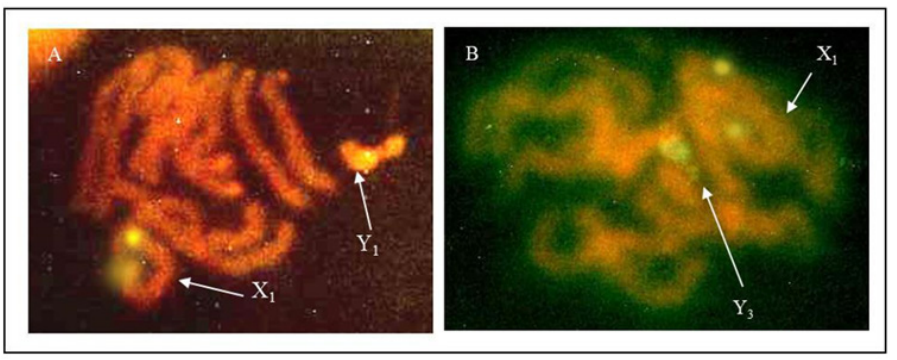

Figure 2 FISH using pkI 8 from Anastrepha fraterculus. A: Reference strain fArglshowing sexual karyotype XIYI. B: Strain 35M sexual karyotype XI Y3. Arrows indicate sexual chromosomes with hybridization signals. 2500x.

\section{Discussion}

A method for localizing the primary sex determination factor in Anastrepha fraterculus by FISH is presented. FISH shows that maleness factor strongly hybridizes the short as well as the long arm of the Y-chromosomes. Weaker marks on the $\mathrm{X}$ chromosomes, point out the persistence of a small subset of genes shared between the Xand Y-chromosome and selective retention and amplification on the Y-chromosome of male determining factors.

Sex chromosomes have evolved -from what was once an ordinary pair of autosomes, ${ }^{23}$ with the $\mathrm{X}$ retaining and the $\mathrm{Y}$ gradually losing most of the ancestral genes. ${ }^{24-26}$ Lahn revealed that four main events of gene recombination were responsible for the origin of $\mathrm{X}$ - and Y-chromosomes. These events caused an inversion and recombination along the regions on Y-chromosome DNA, consequently they cannot linearize anymore with analogue DNA regions present on its partner $\mathrm{X}$-chromosome. This avoided the interchanging of DNA between similar regions present on both sexual chromosomes and facilitated that $\mathrm{X}$ and $\mathrm{Y}$ chromosome segments differentiate from each other. The lack of recombination between the $\mathrm{X}$ and the $\mathrm{Y}$ chromosomes led to loss and differentiation of genes on the $\mathrm{Y}$ chromosome. ${ }^{23}$

We infer that similar rearrangements have taken place between the $\mathrm{X}$ and the $\mathrm{Y}$ chromosomes in Anastrepha fraterculus. Apart from differing in their sizes, $\mathrm{Y} 1 / \mathrm{X} 1=0,66$ and $\mathrm{Y} 3 / \mathrm{X} 1=0,4$, these chromosomal variants differ in their FISH patterns concerning their long arms, suggesting the occurrence of an inversion and a deletion to produce Y3 (Figures $2 \& 3$ ). The Y1 long arm is $60 \%$ hybridized, the Y3 long arm is completely hybridized. At least a deletion occurred to produce the Y3 short arm (Figures $2 \& 3$ ). Y-chromosome variation in A. fraterculus, has been previously revealed through $\mathrm{C}$-banding studies detecting $\mathrm{Y}$ variants. Since all three length ratios $\mathrm{Y} 1 / \mathrm{X} 1$, $\mathrm{Y} 2 / \mathrm{X} 1, \mathrm{Y} 3 / \mathrm{X} 1$, are $0.66,0.5$ and 0.4 respectively, this is pointing out a length gradient associated to the $\mathrm{C}$ - and N-banding patterns previously described. ${ }^{22}$ These data suggest that $\mathrm{Y}$-variants are derived from rearrangements involving the gain or loss of chromosomal segments carrying constitutive heterochromatin, but the maleness factor remains in the proximal region of the long arm next to the centromere of the Y-chromosome.

Furthermore, we had previously found and reported the existence of a triploid $\mathrm{XXY}$ and mosaics $\mathrm{XY} / \mathrm{XXYY}$ which are males. We also found sexual monosomic aneuploids $\mathrm{XO}$ which are females in Anastrepha fraterculus. ${ }^{22} \mathrm{~A}$ transposition from the X-chromosome long arm to the Y-chromosome short arm have been occurred during human evolution..$^{23}$ The author analyzed the chromosomes of sexreversed XX men, rare individuals who look like men but have two X chromosomes instead of one $\mathrm{X}$ chromosome and one $\mathrm{Y}$ chromosome. 
Through DNA hybridization with probes corresponding to regions of the Y chromosome, he discovered that sex-reversed males carried genes from a 140-kilobase region on the short arm of the Y chromosome. ${ }^{24}$ Presumably, this region had been transferred to the $\mathrm{X}$ chromosome during a translocation..$^{25}$ It was found that one gene in this region, ${ }^{26,27}$ the sex-determining region of the Y, or SRY, was the master regulator of sex determination. ${ }^{28}$ The presence of just this region from the $\mathrm{Y}$ chromosome is thus sufficient to cause male development. ${ }^{29-35}$

\section{$\begin{array}{lll}\mathbf{x}_{1} & \mathrm{Y}_{1} & \mathbf{Y}_{3} \\ & \text { 䚁 }\end{array}$}

Figure 3 Ideogram of sexual chromosomal variants studied in Anastrepha fraterculus strains. FISH staining with probe K-I8. Dark grey are hybridization signals.

\section{Conclusions}

Our results show that in Anastrepha fraterculus the $\mathrm{Y}$ chromosome is responsible for sex determination. Further evidence on sexual aneuploids XO females and XXY males strongly support present results. Polymorphisms of the $\mathrm{Y}$, point out that continuous sampling to detect genetic variation is unavoidable for continuous SIT success.

\section{Acknowledgements}

DNA profiles were carried out in the facilities of the laboratory directed by Dr L.A. Quesada-Allué at the Department of Biological Chemistry, FCEyN, University of Buenos Aires, IIBBA-CONICET and Fundación Instituto Leloir, Patricias Argentinas 435, 1405BWE, Ciudad Autónoma de Buenos Aires, Argentina. We are grateful to Dr. L. A. Quesada-Allue for his generosity. In memoriam to Doctor Fanny Manso pioneer on artificial breeding of Anastrepha fraterculus (Wied), making possible to found and to maintain laboratory strains and laboratory populations, developing knowledge on cytogenetics, reproductive behavior and crossings to test compatibilities among germplasms.

\section{Conflicts of interest}

No conflict of interest was reported by the authors.

\section{Funding}

Present research was financed with project funds I.N.T.A. No: 85136 and I.A.E.A., Austria No: B5-ARG-29609.

1994/99- I.N.T.A. No: 85136: "Estudio de los polimorfismos de cromosomas sexuales de Ceratitis capitata y Anastrepha fraterculus mediante técnicas de bandeo e hibridización in situ. Director: Fanny Manso.

2001/06- I.A.E.A., Austria No: B5-ARG-29609: "Induction and utilization of mutations for delineate the complexities of sex determination in the ANASTREPHA FRATERCULUS COMPLEX in association with its sexual chromosomal polymorphisms."

\section{References}

1. Basso Abraham, Alicia Leonor. Reference Karyotypes and Chromosomal Variability: A Journey with Fruit Flies and the Key to Survival. In: Chromosomal abnormalities. Intech Open. 2017.

2. Basso Alicia. Characterization of the components of the "Anastrepha fraterculus Complex” (Anastrepha spp. Diptera: tephritidae, trypetinae) by analysis of chromosomal variability. PhD. Dissertation. Buenos Aires University, Argentina. 2003. 244 p.

3. Basso A, Lifschitz E, Manso F. Determination of intraspecific variation in sex heterochromatin of Ceratitis capitata (Wied.) by C-banding. Cytobios. 1995;23-244.

4. Basso A, Lifschitz E. Size polymorphism of the X-chromosome due to attachment of a B-chromosome in the medfly Ceratitis capitata (Wied.). Brazilian Journal of Genetics. 1995;8(2):165-171.

5. Basso A, F Manso. Are Anastrepha fraterculus chromosomal polymorphisms an isolation barrier? Cytobios. 1998;93:103-111.

6. Basso A, A Sonvico, LA Quesada-Allué et al. Comparison between chromosome variation and DNA polymorphism in the Montecarlo population of Anastrepha fraterculus (Wied.). Second meeting of the working group on fruit flies of the western hemisphere. Viña del Mar, Chile; 1996.

7. Basso A, Sonvico A, Quesada-Allue LA, et al. Karyotypic and molecular identification of laboratory stocks of the South American fruit fly Anastrepha fraterculus (Wied.). Journal of Economic Entomology. 2003;96(4):1237-1244.

8. Bedo DG. Fluorescence banding in mitotic and meiotic chromosomes of the Mediterranean fruit fly, Ceratitis capitata (Diptera Tephritidae). Genome. 1989;32;580-588.

9. Bridges CB. Triploid intersexes in Drosophila melanogaster. Science. 1921;54:252-254.

10. Bridges CB. Sex in relation to chromosomes and genes. Am Nat. 1925;59:127-137.

11. Charlesworth B. The evolution of chromosomal sex determination and dosage compensation. Current Biology. 1996;6(2):149-162.

12. Heard Edith, Christine Disteche. Dosage compensation in mammals: fine-tuning the expression of the $\mathrm{X}$ chromosome. Genes Dev. 2006;20(14):1848-1867.

13. Knipling E. Possibilities of insect control or eradication through the use of sexually sterile males. J Econ Entomol. 1955;48:459-462.

14. Knipling EF. The use of insects for their own destruction. $J$ Econ Entomol. 1960;53:415-420.

15. Krafsur ES. Sterile insect technique for suppressing and eradicating insect population: 55 years and counting. J Agric Entomol. 1998;15:303317.

16. Koopman P, J Gubbay, N Vivian, et al. Male development of chromosomally female mice transgenic for Sry. Nature. 1991;351(6322):117-121.

17. La Chance L. Genetic strategies affecting the success and economy of the sterile insect release method. Genetics in relation to insect management. The Rockefeller Found. NY; 1979.

18. Lahn B, Page D. Four evolutionary strata on the human X chromosome. Science. 1999;286:964-967.

19. Lifschitz Ernesto. Sex determination in Ceratitis capitata. In: Report of the Consultant's Meeting on a genetic sexing mechanism for the Mediterranean fruit fly Ceratitis capitata. Vienna, Austria (Mimeograph): FAO/IAEA. 1980. p. 2-4.

20. Lifschitz E, Cladera J. Ceratitis capitata cytogenetics and sex determination". Fruit flies: Their biology, natural enemies and control, Robinson AS, Hooper G, editors. Elsevier, Amsterdam; 1989;3b:3-1 1.

21. Lifschitz E, F Manso, JL Cladera, et al. Genetic sex-sorting mechanisms for the Mediterranean fruit fly. Research Co-ordination Meeting on the Development of Sexing Mechanisms in Fruit Flies through Manipulation of Radiation-induced Lethals and other Genetic Measures, edited by J.F.I. Division. IAEA, Vienna, Austria. 
22. Lifschitz E, Manso FC, Basso A. Karyotype study of the South American Fruit Fly, Anastrepha fraterculus (Wied.) in Argentina. In: IAEA, editor. The South; 1999.

23. American Fruit Fly, Anastrepha fraterculus (Wied.): Advances in Artificial Rearing, Taxonomic Status and Biological Studies. IAEA, Vienna. [IAEA-TECDOC-1064.] Lukusa T, J P Fryns \& H van der Berghe. The role of the Y-chromosome in sex determination. Genet Couns. 1992;3(1):1-11.

24. Manso FC, JL Cladera, E Lifschitz. Screening for a female-limited temperature-sensitive lethal mutation induced on a Y-autosome translocated strain, in Ceratitis capitata, pp. 219-225 in Proceedings of the Second International Symposium on Fruit Flies, edited by A.P. Economopoulos. Elsevier. Amsterdam, The Netherlands. Manso FC \& E Lifschitz. New genetic methodology to improve the efficiency of the sterile male technique in the control of the Mediterranean fly Ceratitis capitata. Science and Research. 1992;44:225-228.

25. Manso FC, A Basso. Notes on the present situation of Anastrepha fraterculus in Argentina. In: IAEA (Ed.) The South American Fruit Fly, Anastrepha fraterculus (Wied.): Advances in Artificial Rearing, Taxonomic Status and Biological Studies. IAEA, Vienna. [IAEATECDOC-1064. 1999.

26. McCreer T, T Helentjaris. Production of DNA hybridization probes with digoxigenin-modified nucleotides by random hexanucleotide priming, in Methods in Molecular Biology. Protocols for nucleic Acid Analysis by Nonradioactive Probes (Isaac, P. G.), Humana Press, Totowa, NJ; 1994. pp. 73-76.
27. McLaren A. The making of male mice. Nature. 1991;351:96.

28. Page DC, De la Chapelle A, Weissenbach J. Chromosome Y-specific DNA in related human XX males. Nature. 1985;315:224-226.

29. Page D, Harper M, Love J, et al. Occurrence of a transposition from the $\mathrm{X}$ chromosome long arm to the Y chromosome short arm during human evolution. Nature. 1984;311:119-123.

30. Page David. On low expectations exceeded; or, the genomic salvation of the Y chromosome. Am J Hum Genet. 2004;74:399-402.

31. Sonvico A, Manso F, Quesada-Alluè LA. Discrimination between the immature stages of Ceratitis capitata and Anastrepha fraterculus (Diptera: Tephritidae) populations by random amplified polymorphic DNA polymerase chain reaction. J Econ Entomol. 1996;89:1208-1212.

32. Weissenbach L, F Rouyer. The Y chromosome and sex determination. Reprod Nutr Dev Suppl. 1990;1:27s-38s.

33. Willhoeft U, Franz G. Identification of the sex-determining region of the Ceratitis capitata Y chromosome by deletion mapping. Genetics. 1996;144(2):737-745.

34. Willhoeft U, Franz G. Analysis of the Ceratitis capitata Y chromosome using in situ hybridization to mitotic chromosomes.

35. Zapater M, A Robinson. Sex chromosome aneuploidy in a male linked translocation in a male linked translocation in Ceratitis capitata. Can J Genet Cytol. 1986;281:161-167. 